\title{
TRAMANDO GÊNERO NOS CONTOS DE MACHADO DE ASSIS
}

\author{
Gender Patterns in Short of Machado de Assis \\ Diseño de Género en los Cuentos de Machado de Assis
}

Maria José Pereira Rocha

\begin{abstract}
Resumo: Este artigo privilegia uma reflexão sobre as tramas do masculino e do feminino nos contos de Machado de Assis. Nessa medida, o texto opta por uma análise singular elaborada sob a ótica do neopragmatismo como teoria ad hoc, entendida como corrente filosófica que privilegia a conversação. O eixo que guia a análise é a noção de redescrição de R. Rorty como tarefa da imaginação. Esse exercício permite descrever a nós e aos outros buscando tecer uma nova abordagem. Com base nessa compreensão, enfatiza-se elementos que possibilitam repensar as urdiduras do masculino e do feminino nos contos do referido autor. A tentativa é a de tramar e reinventar uma história com base nos contos de Machado de Assis que servem de pretexto para engendrar idéias e reflexão que irão compor um novo significado.
\end{abstract}

Palavras-chave: Gênero; Neopragmatismo; Redescrição.

Abstract: This article focuses on a reflection on the plots of male and female in the stories of Machado de Assis. This way, the text adopts a unique analysis drawn from the perspective of neo-pragmatism as an ad hoc theory, understood as a philosophical movement that focuses on conversation. The shaft that drives the analysis is the notion of redescription of R. Rorty as the task of imagination. This exercise allows us to describe ourselves and others seeking to make a new approach. Based on this understanding, we emphasize the elements that allow rethink the warps of male and female in the tales of the author. The attempt is to devise and reinvent a story based on stories by Machado de Assis that serve as a pretext to engineer ideas and reflection that will compose a new meaning.

Keywords: Gender; Neopragmatism; Redescription.

Resumen: Este artículo se centra en una reflexión sobre las tramas de los hombres y de las mujeres en los cuentos de Machado de Assis. Como tal, el texto adopta un análisis singular elaborado desde la perspectiva del neo-pragmatismo como una teoría ad hoc, entendida como un movimiento filosófico que se centra en la conversación. El eje que guía el análisis es la noción de redescripción de R. Rorty (1999) como la tarea de la imaginación. Este ejercicio nos permite describir a nosotros mismos y a los otros al buscar hacer un nuevo enfoque. Sobre la base de este entendimiento, hacemos hincapié en los elementos que permitan repensar los trazados de hombres y mujeres en los cuentos del autor. El intento consiste en diseñar y reinventar una historia basada en cuentos de Machado de Assis, que sirven como pretexto para engendrar ideas y la reflexión que han de compor un nuevo significado.

Palabras-clave: Género; Neopragmatismo; Redescripción.

Quando desenvolvo uma reflexão e escrevo um texto sempre me deparo com o desafio de encontrar a faísca da novidade que acende o estopim da fogueira do imaginário e atiça as labaredas do desejo de inventar novas possibilidades. Uma frase... uma pintura... uma poesia... uma novela... um filme... uma conversa... um conto... são fontes inesgotáveis de idéias, que surgem da forma mais inusitada. Em casa com a família, no bar com amigos ou em outro lugar qualquer se torna possível faiscar e dar asas a um pensamento que vira chamas.

A motivação, desta vez, surgiu durante uma conversa com minha filha Moara, que estava estudando os contos de Machado de Assis na aula de Literatura. Ela me falou das suas interpretações dos textos. Este momento foi mágico, porque o entusiasmo dela conseguiu contagiar-me e eu desejei ler também os contos. Esta experiência levoume a redescobrir Machado de Assis. Lemos - Moara e eu
- dois contos: O Caso da Vara (Assis, 1997a) e Noite de Almirante (Assis, 1997b).

Ao compartilharmos nossas reflexões sobre esses contos, descobrimos que mulheres e homens retratados nas histórias não se encaixavam completamente nos papéis estabelecidos e construídos socialmente de maneira fixa, como é de praxe encontrar em algumas análises das diversas áreas do conhecimento. Refiro-me aos padrões que estabelecem que papel deve cada gênero desempenhar social e culturalmente. A experiência relacional que se dá entre o masculino e o feminino na família, na escola, na sociedade e na cultura é o que atualmente se denomina de gênero.

Essa noção de gênero pode ser entendida como a construção social do modo de ser mulher e do modo de ser homem, que parte da distinção entre os dois sexos. É importante destacar que essa dicotomia nem sempre tem a 
mesma conotação para todas as culturas (Lamas, 1986). Inicialmente, o padrão origina-se da diferenciação sexual biológica e, posteriormente, por uma diferenciação social por meio da divisão social do trabalho.

Dessa perspectiva, a distinção entre sexo e gênero pode ser proposta da seguinte forma: o sexo refere-se à identidade biológico-genética e o gênero, à identidade designada e adquirida socialmente, isto é, uma construção cultural que implica certas maneiras de se manifestar, sentir e atuar de acordo com o sexo.

No meu texto Feminismo e Cinema: reflexões metodológicas sobre o filme Nem Gravata Nem Honra (Rocha, 2006), faço um percurso teórico que me leva a constatar que boa parte dos conceitos e teorias vigentes não alcança e nem abrange a totalidade a que se propõe ao tentar definir as diferenças entre homens e mulheres. Identifica-se um espaço favorável à ambiguidade. Isso porque a fronteira entre a prática do masculino e do feminino é cada vez mais tênue e diluída. Encontram-se homens e mulheres com as características tradicionais e mulheres e homens que se movimentam em situações de profunda fragilidade e fortaleza transitando nos mesmos espaços, e, muitas vezes, não é possível demarcar com clareza as características designadas e correspondentes ao masculino e ao feminino.

Tendo em mente essa linha de pensamento, tento não cair no engodo de todo arcabouço teórico que reafirma essas posições que estabelecem as diferenças entre o masculino e o feminino de maneira fixa e sem mobilidade entre o que está definido para os papéis designados a cada sexo/gênero. Nesse sentido, e consciente desse desafio, articulo essa visão dos papéis masculino e feminino que aparecem nos referidos contos como uma brecha que se abre para uma nova possibilidade de fiar um outro enredo.

Nesse caso, confesso que, após essa conversa com minha filha, fui profundamente instigada a fazer um exercício no qual pudesse tramar novos sentidos com uma redescrição dessas imagens narradas por Machado de Assis e, ao mesmo tempo, tecer uma teia que abarcasse o mito de Penélope para elaborar uma nova abordagem ao compor com diferentes fios os liames das três histórias.

\section{O Caso da Vara, Noite de Almirante e Penélope}

O primeiro conto, O Caso da Vara, relata a fuga de um jovem seminarista, Damião, que, no auge do desespero, procura a ajuda de Sinhá Rita, uma viúva amiga de seu padrinho João Carneiro. Com argumentos contundentes, o jovem Damião convence Sinhá Rita a ajudá-lo depois de uma breve discussão. Ela ordena ao criado que vá buscar João Carneiro, padrinho do rapaz, para que este o tire da enrascada, ou seja, abandonar o seminário. O padrinho do rapaz é um emissário que, a contragosto, assume o papel de intermediário, indo falar com o pai de Damião.
Enquanto espera o retorno do padrinho, Damião conversa, senta-se à mesa e conta anedotas para Sinhá Rita e as criadas. Uma destas distrai-se do bordado, e Sinhá Rita adverte-a de que, se não terminar a tarefa, será castigada. O rapaz promete a si salvá-la caso ela não termine sua tarefa. O padrinho retorna sem uma definição do pai de Damião. E, nesse momento, Sinhá Rita, ao perceber que a criada não conseguiu terminar a tarefa, segura-a pela orelha e pede ao rapaz que lhe dê uma vara que está próxima a ele. Damião pensa, sofre, mas, contudo, decide entregá-la a Sinhá.

Por sua vez, o segundo conto, Noite de Almirante, narra a história de Deolindo Venta-Grande e sua amada Genoveva. Eles prometeram fidelidade um ao outro por ocasião da viagem de instrução que ele faria como marujo por oito ou dez meses. Deolindo alimentou um sonho que foi compartilhado por seus companheiros de viagem de que, ao regressar, teria uma noite de almirante com sua amada.

Mas, contrariamente ao que ele imaginava, Genoveva fugiu com outro, quebrando a promessa de esperá-lo. Para sua surpresa, ela confirma que, realmente havia prometido esperar seu retorno, mas se apaixonou pelo mascate e não podia fazer mais nada. Ele entrega-lhe, então, um par de brincos que lhe comprou de presente e, esperançoso, aguarda que ela mude de idéia em relação ao outro pretendente. Isso, porém, não acontece. Deolindo ameaça matar-se, porém ela não lhe faz caso, acreditando que ele esteja com ciúmes. Ele não se mata e, ao regressar à corveta da marinha, induz seus amigos marujos a acreditarem que teve uma noite de almirante.

Fazendo um contraponto com essas duas histórias, apresento a seguir uma breve síntese do mito de Penélope que, segundo a lenda grega, narra a história da mulher de Ulisses, que lhe permaneceu fiel em sua longa ausência. Usando de astúcia, alegava aos pretendentes que não se casaria enquanto não terminasse de fazer uma grande tela, que tecia durante o dia e desmanchava à noite. Tal estratégia era um segredo mantido solitariamente.

Retomando o fio que tece as três histórias, a conversa que realizei com minha filha sobre os contos de Machado de Assis e sua aula de literatura, tive a intuição de que é possível ilar tudo isso com a reflexão de Rorty (2000) sobre a educação, em particular no que se refere a duas idéias desse autor, a seguir.

A primeira idéia encaixa-se no realce que este autor dá ao legado de Dewey ao afirmar que a grande contribuição deste para a teoria da educação consiste em desmistificar a idéia de que a educação é uma questão de induzir a verdade ou deduzir a verdade. Ao frisar essa idéia, Rorty (2000, p. 87) considera que a educação primária e secundária será sempre uma forma de introduzir o jovem nos assuntos, crenças e conhecimentos que seus anciãos tomam como verdadeiro, seja isto verdadeiro ou não.

Ao colocar a questão nestes termos, este autor reitera que a educação superior não-profissionalizante pode ser 
vista como um processo que incita dúvidas, estimula a imaginação e possibilita desafiar o consenso dominante. Se a educação pré-college forma indivíduos autocriados, então a questão sobre o fato de estarem ensinando a verdade aos estudantes pode ser negligenciada (Rorty, 2000, p. 87). Compartilhando das idéias de Dewey, Rorty (2000, p. 95) resgata a função social dos colleges americanos, como a de ajudar os estudantes a verem que a narrativa nacional, em torno da qual sua socialização está centrada, é uma coisa em aberto. Este conjunto de idéias reflete um significativo processo que se dá mediante a inculcação dessa narrativa de liberdade e esperança como o núcleo do processo de socialização (Rorty, 2000, p. 91).

Em virtude de situações como essas descritas, Ghiraldelli Jr. (2006) destaca que a filosofia de Rorty distingue-se pela ênfase na esperança que irá derivar no impulso para sonhar e tecer novas possibilidades de criar versões melhores de nós.

A segunda idéia relaciona-se com o enfoque que Rorty (2000) dá a educação não-profissionalizante, ao expor em linhas gerais que, em tais circunstâncias de aprendizagem, é de suma importância que esse processo se efetive com professores vivos, e não por meio de computadores e notas de lições mimeografadas, isso porque os estudantes necessitam ter os olhos comprometidos livremente, antes de qualquer coisa, por meio de seres humanos. Ele considera que a liberdade de cátedra e a liberdade acadêmica são muito mais amplas que os procedimentos determinados pelos currículos institucionais adotados para o exercício da educação não-profissionalizante (Rorty, 2000, p. 96).

Em afinidade com esta linha de raciocínio, este autor ainda defende e ressalta que tais compromissos de liberdade são as ocasiões de relacionamentos eróticos entre professor e estudante, tal como Socrátes e Allan Bloom celebram e que Platão, infelizmente, tentou capturar em uma teoria da natureza humana e no currículo das artes liberais. Mas o amor é notoriamente não teorizável. Tais relacionamentos eróticos são ocasiões de crescimento; sua ocorrência e seu desenvolvimento são tão imprevisíveis quanto o próprio crescimento em si, ainda que nada de importante aconteça na educação superior não-profissionalizante sem eles. Nessa compreensão, Rorty (2000, p. 96-97) ainda revela que a maioria desses relacionamentos ocorre com os professores já mortos que escreveram os livros que os estudantes estão lendo, mas alguns acontecem com os professores vivos que estão ministrando as lições.

Nesse sentido, o autor deixa claro que, em ambos os casos, o cortejamento que vai e volta entre o professor e o estudante, conectando-os em um relacionamento que tem pouco a ver com a socialização e muito a ver com a autocriação, é o principal meio pelo qual as instituições de uma sociedade liberal conseguem ser transformadas. A menos que tais relacionamentos sejam criados, os estudantes nunca perceberão que as instituições democráticas são boas para tornarem possível a invenção de novas for- mas de liberdade humana, conversando sobre liberdades nunca antes conversadas (Rorty, 2000, p. 97).

O fascínio pela arte de exercitar a redescrição como uma tarefa da imaginação condiz perfeitamente com o fio que teceu o diálogo que tive com Moara sobre as histórias dos contos e que me permitiu visualizar uma tessitura com as idéias de Rorty no que se refere à apropriação da narrativa de liberdade e esperança como o núcleo do processo de socialização.

Ao estabelecer nexos entre termos, situações ambíguas e contraditórias, busco uma trama que pode ser tecida com as cores e os matizes das histórias narradas nos contos, tendo elementos comuns entre eles como a fidelidade, a ausência e o segredo. Considerando tudo isso, é relevante ainda salientar que a fidelidade nas três histórias não tem a mesma configuração. No que tange ao primeiro conto, o ato de ser fiel não provem de uma relação amorosa, ela é pessoal e circunstancial. Já no segundo, ela se dá em função de uma relação amorosa marcada por um juramento de fidelidade entre o casal. Na última história, a fidelidade acontece também numa relação amorosa. É uma fidelidade exercida de forma unilateral e em função do outro.

Porém, antes de explorar esses aspectos, é necessário apresentar a descrição dos comportamentos masculinos e femininos como papéis que estão caracterizados no primeiro conto da seguinte forma: Damião - jovem, espantado, medroso e fugitivo; padrinho - moleirão, sem vontade; Sinhá Rita - viúva, vivia de ensinar a fazer renda, crivo e bordado; pai - zangado e violento. Não há dúvida de que a fidelidade, a ausência e o segredo movem o desenrolar dessa narrativa, criando um espaço propício para a aprendizagem.

Em conexão com o exposto, a primeira idéia a ser destacada é a de um processo de ensino-aprendizagem como ação pedagógica que ocorre no encontro entre Damião e Sinhá Rita. Desesperado para abandonar o seminário, Damião usa sua habilidade comunicativa de forma adequada para convencer Sinhá Rita a ajudá-lo. Ardilosamente, ele revela à sua protetora que ela pode, que só ela tem poder para fazer alguma coisa por ele. Sinhá é fisgada pelo argumento de que ela sabe, pode mandar e exercer o poder sobre o padrinho que é enviado para conversar com o pai de Damião.

Diante de tais circunstâncias, o primeiro aprendizado desse personagem começa quando ele se descobre inicialmente triste pela situação na qual está envolvido e, com o desenrolar da história, aprende que deve aparentar estar triste. Mediante seu desejo de alterar a situação que está vivendo, ele aprende que o êxito e a solução do seu problema tem como condição a demonstração do sentimento de tristeza. Para isso, ele finge, aparenta estar triste, suspira alto e quer que os outros percebam o que está sentindo.

O seu segundo momento de aprendizado começa quando ele faz a promessa de defender a criada que se distraiu na tarefa do bordado. Ele promete a si ajudá-la, porém, 
quando percebe que sua liberdade pode estar ameaçada, é fiel apenas a si, faz uma escolha e opta por entregar a vara. Destaca-se aqui nesse processo a questão da fidelidade e a liberdade de escolha como chaves para compreender como os papéis masculinos e femininos são construções culturais que estão sujeitas a mudanças, dependendo do que está em jogo. Pode-se deduzir que a armadilha de Damião é a possibilidade da fidelidade que coloca em xeque a sua promessa no momento em que se apresenta a oportunidade de livrar a criada da surra ou perder sua liberdade, voltando para o seminário. Ele escolhe entregar a vara.

Nesse sentido, diante da sua necessidade de permanecer livre e da escolha que faz, ele toma consciência de que as pessoas aprendem as coisas, os sentimentos, e de que também as pessoas mudam, e que ser sincero nem sempre é a melhor opção. Dessa forma, homens e mulheres não fazem coisas que são ruins por que querem. Elas fazem porque acham que é a melhor opção.

Muitas vezes, necessitamos de muita coragem para desfazermos de nossas idéias, crenças que se cristalizaram, e não sabemos como extrair novos brilhos. Por mais que a crença em determinadas teorias leve a um desmoronamento das referências que defendemos, chega um momento em que é preciso desvencilhar-se delas para poder descobrir novas possibilidades de pensar.

Refiro-me à crença que indica que homens e mulheres são diferentes no exercício dos papéis masculinos e femininos. Essa é uma armadilha que, ao puxar o fio que tece as três histórias, é desmontada. O conto anterior revela uma mulher com poder de resolver situações e um rapaz inseguro que aprende a fingir, ser fiel a si, a guardar segredo, escolher e se adaptar de acordo com o momento. Ele descobre que não pode cumprir a promessa que havia feito, e escolhe entregar a vara, salvando sua pele.

No caso de Noite de Almirante, as características dos personagens podem ser descritas da seguinte forma: Deolindo Venta Grande - a fina flor dos marujos, moço impaciente e fiel; Genoveva - caboclinha de vinte anos, fiel, esperta, olhos negros e atrevidos.

No que tange a essa história, os elementos que sobressaem são a promessa de fidelidade, a ausência, a quebra da fidelidade e a mentira. Como processo pedagógico, é interessante realçar que Genoveva promete ser fiel a Deolindo, mas não cumpre sua promessa; já Deolindo a cumpre e 'quebra a cara'. Seu aprendizado pode ser inferido da seguinte forma: que as coisas, os sentimentos e as pessoas mudam. Ser sincero nem sempre é a melhor opção. Ele aprendeu que não pode ser sincero sempre e que nem sempre as promessas serão cumpridas.

Genoveva não é fiel a Deolindo. Ela é fiel a ela unicamente. Dona da própria vida, sabe o que quer, tem uma sinceridade brutal. Demonstra capacidade de lidar com as coisas embaraçosas e dominar as situações complicadas e, ao mesmo tempo, de se adaptar e mudar de um estágio a outro. Passa do susto à tentativa de preocupação, e logo se mostra gentil, como se não houvesse acontecido nada.
Pode-se enfatizar que essa é uma característica das mulheres que é realçada no conto: capacidade de adaptação rápida. Já Deolindo procura se adaptar ao perceber que as pessoas prometem e não cumprem, e, depois de refletir, constata que elas mudam e são diferentes. Dá para inferir que os homens têm mais dificuldades de adaptarem-se a situações como as que ele vivenciou, pelas quais aprende que é melhor não fazer nada e mentir.

Se se levam em conta os comportamentos masculinos e femininos, é praxe considerar que o homem sempre deu a última palavra e é o que mais sobressai e comanda as ações. Mas nos dois textos, quem dá a última palavra são elas. O aprendizado aqui difere de muitas outras histórias, como a de Penélope, por exemplo, que apresenta as seguintes características: fidelidade, paciência, esperteza, intuição, planejamento, pensamento matemático e, por fim, sabe traçar estratégias. Sua atitude sugere a dialética do fixo e do móvel, do contínuo e do descontínuo. Em que pesem todas essas habilidades, elas só tiveram um único foco: garantir a fidelidade a Ulisses.

Olhar para a história e as características de Penélope é uma tarefa que me coloca num incômodo espaço da contradição e ambigüidade no sentido de que posso visualizá-la como alguém que é portadora dessas qualidades que são reveladas por meio da atividade de tecer e destecer uma tela com um propósito definido. Infere-se que essas qualidades foram desenvolvidas com um único foco, o de ser fiel a Ulisses, e tudo convergiu para essa fidelidade. Mas, ao que tudo indica, esse comportamento feminino que pode ser traduzido como o símbolo da fidelidade conjugal não ajuda Penélope como representante do sexo feminino. Ao contrário, faz dela prisioneira dessa condição e reflete a submissão, a heteronomia que se prolongou por duas décadas. Pode-se deduzir que essa é uma face do mito que expõe a contradição entre a prática do papel feminino e as habilidades que asseguram o exercício cego da fidelidade.

Creio que o aprendizado pode acontecer se se conseguir visualizar o escancaramento desse papel feminino envolto tanto no espaço da ambigüidade como no processo de contradição do ser feminino.

Ao tecer essa trama da linguagem em que fiz um esforço para aproximar Machado de Assis e o pensamento de Rorty, descubro que a motivação se deu quando percebi que os contos me instigavam pela boa história e pela forma como foram contadas. Machado abusou da inteligência, ficando evidente sua habilidade para contar a história e enredar o leitor. Rorty sugere a redescrição como um exercício da imaginação para criar novas possibilidades de narrar uma história.

Pensando muito no primeiro conto e na configuração da fidelidade de Damião, é possível ainda afirmar que ele preferiu salvar a sua pele e deixar a menina sofrer as conseqüências do atraso da tarefa. Tal situação vista nesse espaço de ambigüidade e contradição incomoda-me, e, ao incomodar-me, busco um outro eixo de reflexão que me 
apresente uma versão mais edificante dos gêneros masculino e feminino.

Os dias passam e nada de novo aparece no cenário dos meus pensamentos conturbados. Até que surge outra possibilidade de reflexão, vinculada ao filme Sombras do Passado (Gallenberger, 2004) que narra a história de duas crianças indianas, Ravi (Prashant Narayanan) e Masha (Tanishta Chatterjee), que trabalham como operárias numa fábrica de carpetes próxima a Calcutá. Ravi trabalha com um único objetivo somente: deixar a fábrica. Porém, quando ele descobre que o diretor da fábrica quer vender Masha como uma escrava branca, ele sacrifica todas as suas economias para comprar a liberdade dela. Anos depois, o jovem sai da fábrica ao encontro de Masha, que se tornou uma dançarina de um dos bordéis da cidade.

A mensagem do filme Sombras do Passado minimiza a narrativa dura e real da primeira história de Machado de Assis. O contraponto é dado pelo menino Ravi, que, ao tomar conhecimento de que a menina amada será vendida para ser explorada sexualmente, decide sacrificar suas economias e salvá-la, sofrendo em seu lugar o peso do trabalho na fábrica. $\mathrm{O}$ aprendizado pode ser confirmado pela solidariedade de Ravi, que o leva a perder as economias e a liberdade em favor da liberdade da menina Masha.

Depois de tecer este texto, perpassa-me, todavia, um questionamento: será que não é paradoxal utilizar Machado de Assis para fazer uma redescrição de gênero? Ocorremme duas possíveis respostas: a primeira vem de um argumento da filosofia pragmatista que aconselha a sua adoção como filosofia ad hoc adequada para os fins que estabeleci ao iniciar essa reflexão; a segunda resposta vem das estratégias redescritivas de Rorty. Nesse enlace, diria que as três estratégias são imprescindíveis para o exercício de qualquer redescrição. Neste artigo em particular, o elo que me conecta aos contos de Machado de Assis liga-se especificamente à terceira estratégia redescritiva que, segundo Ghiraldelli Jr. (2005, p. 17), acontece quando "apresentamos histórias que para muitos parecem pouco plausíveis, histórias que dizem coisas inaceitáveis, uma vez que são, não raro, incompreensíveis". A conduta de Damião e Ravi, para muitos, pode soar muito louca e sem sentido no contexto da reflexão desenvolvida até agora, mas, ao guiar-me pelas estratégias descritivas, o meu intento é justamente buscar argumentos que toquem e, ao tocar, sejam capazes de criarem novas possibilidades de reflexão.

Se, de um lado, Damião, Genoveva, Deolindo e Penélope mostram uma face de um desenho real não muito atrativo no qual fazer uma opção é uma garantia de aprendizagem, de sobrevivência e de adaptação aos papéis masculinos e femininos, por outro, a outra face é a contraposição em que se tecem outras habilidades do na narrativa do filme, podem ser compreendidas como um contexto no qual se enxerga o amor como relação de vida e como ato pedagógico que pode gerar seres humanos livres, porque está baseado numa crescente esperança que permite uma liberdade extrema nascida de um sacrifício, para tornar possível a liberdade do outro, ainda que possa parecer pouco plausível.

\section{Referências}

Assis, M. (1997a) Páginas recolhidas. São Paulo: Globo.

Assis, M. (1997b) Histórias sem data. São Paulo: Globo.

Gallenberger, F. (Produtor e Diretor) (2004) Sombras do Passado [Filme-vídeo]. Alemanha.

Rorty, R. (2000) Educação como socialização e como individualização. Em P. Ghiraldelli Jr. (Trad.), O que você precisa saber sobre filosofia da educação (pp. 81-104). Rio de Janeiro: DP\&A.

Ghiraldelli Jr., P. (2005) Uma nova agenda para filosofia. Em R. Rorty, Pragmatismo e Política (pp. 08-23). São Paulo: Martins.

Ghiraldelli Jr., P. (2006) Escola de Frankfurt e pragmatismo: em espelhos. Em P. Ghiraldelli Jr. \& R. Rorty, Ensaios pragmatistas sobre subjetividade e verdade (pp. 09-24). Rio de Janeiro: DP\&A.

Lamas, M. (1986). La antropologia feminista y la categoria género. Nueva Antropologia, México, v. VIII, n. 30, pp. 173-198.

Rocha, M. J. P. (2006). Feminismo e cinema: reflexões metodológicas sobre o filme Nem gravata nem honra. Em: V. Vidal, \& S. Castro (orgs.). A questão da verdade: da metafísica moderna ao pragmatismo [pp. 160-168]. Rio de Janeiro: 7 Letras; Faperj.

Maria José Pereira Rocha - Doutora em Educação pela Faculdade de Filosofia e Ciências da Universidade Estadual Paulista Júlio de Mesquita Filho (Unesp) de Marília/SP. Professora Adjunta no Departamento de Filosofia e Teologia da PUC-Goiás e no Programa de Pós-Graduação - Mestrado em Serviço Social (PPSS-PUC-Goiás). Coordenadora da Rede Goiana de Pesquisa e Estudos de Gênero da Fundação de Amparo a Pesquisa de Goiás (Fapeg). Pesquisadora no Programa Interdisciplinar da Mulher - Estudos e Pesquisas (Pimep), no Núcleo de Estudos e Pesquisa em Estado, Sociedade e Cidadania (Nupesc-SER - PUC-Goiás), inserida na Linha de Pesquisa Política Social, Movimentos Sociais e Cidadania, no Centro de Estudos em Filosofia Americana e no Núcleo de Investigação de Gênero (NIG) da UCG. Endereço Institucional: PUC-Goiás / Pró Reitoria de Assuntos Comunitários e Estudantis, Programa Interdisciplinar da Mulher Estudos e Pesquisas. Av. Universitária, no 1440 - Setor Universitário CEP: 74.605-010 - Goiania-GO. Emai: maze@cultura.com.br

Recebido em 12.10.2010

Aceito em 06.04.2011 